\title{
The Effects of Compliance with Nutritional Counselling on Body Composition Parameters in Head and Neck Cancer Patients under Radiotherapy
}

\author{
D. Hopanci Bicakli,, ${ }^{1}$ O. Ozkaya Akagunduz, ${ }^{2}$ R. Meseri Dalak, ${ }^{3}$ M. Esassolak, ${ }^{2}$ \\ R. Uslu, ${ }^{1}$ and M. Uyar ${ }^{4}$ \\ ${ }^{1}$ Department of Medical Oncology, Ege University School of Medicine, Bornova, 35100 Izmir, Turkey \\ ${ }^{2}$ Department of Radiation Oncology, Ege University School of Medicine, Bornova, 35100 Izmir, Turkey \\ ${ }^{3}$ Department of Nutrition and Dietetics, Ege University Izmir Ataturk School of Health, Bornova, 35100 Izmir, Turkey \\ ${ }^{4}$ Department of Anesthesiology and Intensive Care, Ege University School of Medicine, Bornova, 35100 Izmir, Turkey \\ Correspondence should be addressed to D. Hopanci Bicakli; deryahopanci@hotmail.com
}

Received 23 August 2016; Revised 9 November 2016; Accepted 12 December 2016; Published 2 January 2017

Academic Editor: Rémy Meier

Copyright ( 2017 D. Hopanci Bicakli et al. This is an open access article distributed under the Creative Commons Attribution License, which permits unrestricted use, distribution, and reproduction in any medium, provided the original work is properly cited.

\begin{abstract}
Background. Radiotherapy (RT) has been associated with increased risk of malnutrition in cancer patients, particularly in those with head and neck cancer (HNC). The aim of this prospective study was to evaluate the effects of compliance of patients with individual dietary counselling on body composition parameters in HNC patients under RT. Material and Methods. Sixty-nine consecutive patients (mean age: $61.0 \pm 13.8$ ) were prospectively followed. Bioelectrical impedance analysis (BIA) was performed to determine body composition parameters before, in the middle of, and at the end of RT. All patients received nutritional counselling and majority of them (94.6\%) received oral nutritional supplement (ONS) during RT or chemoradiotherapy. If a patient consumed $\geq 75 \%$ of the recommended energy and protein intake via ONS and regular food, he/she was considered to be "compliant" $(n=18)$, while those who failed to meet this criteria were considered to be "noncompliant" $(n=30)$. Results. Body mass index, weight, fat percentage, fat mass, fat free mass, and muscle mass did not decrease significantly over time in compliant patients, but in noncompliant patients, all of these indices decreased significantly from baseline compared to the end of treatment $(p<0.001)$. Hand grip strength did not differ significantly between the two groups at baseline and over time in each group. When retrospectively evaluated, heavy mucositis was less commonly observed in compliant than noncompliant patients (11.1\% versus $88.9 \%$, resp.) $(p<0.009)$. Conclusion. We conclude that body composition parameters were better in head and neck cancer patients considered as compliant with nutritional counselling than noncompliant ones during RT period.
\end{abstract}

\section{Introduction}

Head and neck cancer (HNC) refers to tumours of all anatomical structures that extend from the nasopharynx to the cervical oesophagus. Environmental factors such as smoking and alcohol consumption may contribute to development of HNC [1]. Cancer treatments are associated with increased risk of nutritional deterioration. Radiotherapy (RT) and/or chemoradiotherapy (CRT) induce symptoms such as mucositis, chewing and swallowing difficulties, anorexia, and xerostomia $[2,3]$. In studies including only HNC patients, it is stated that, along with other problems related to anatomical localization of the tumour, these symptoms may lead to weight loss in around $50 \%$ of cases under RT [2,3] and in as much as $80 \%$ of cases under CRT with likelihood of nausea and vomiting, loss of taste, and loss of appetite caused by the toxicity of the CRT [4]. The reasons of weight loss in $20-30 \%$ of cases who lost are related severe mucositis and dysphagia in a similar patient population [5]. Severe weight loss has been associated with a reduction in physical activity, an increase in treatment related toxicity, a poor response to treatment, and increase in susceptibility to infection due to reduction in 


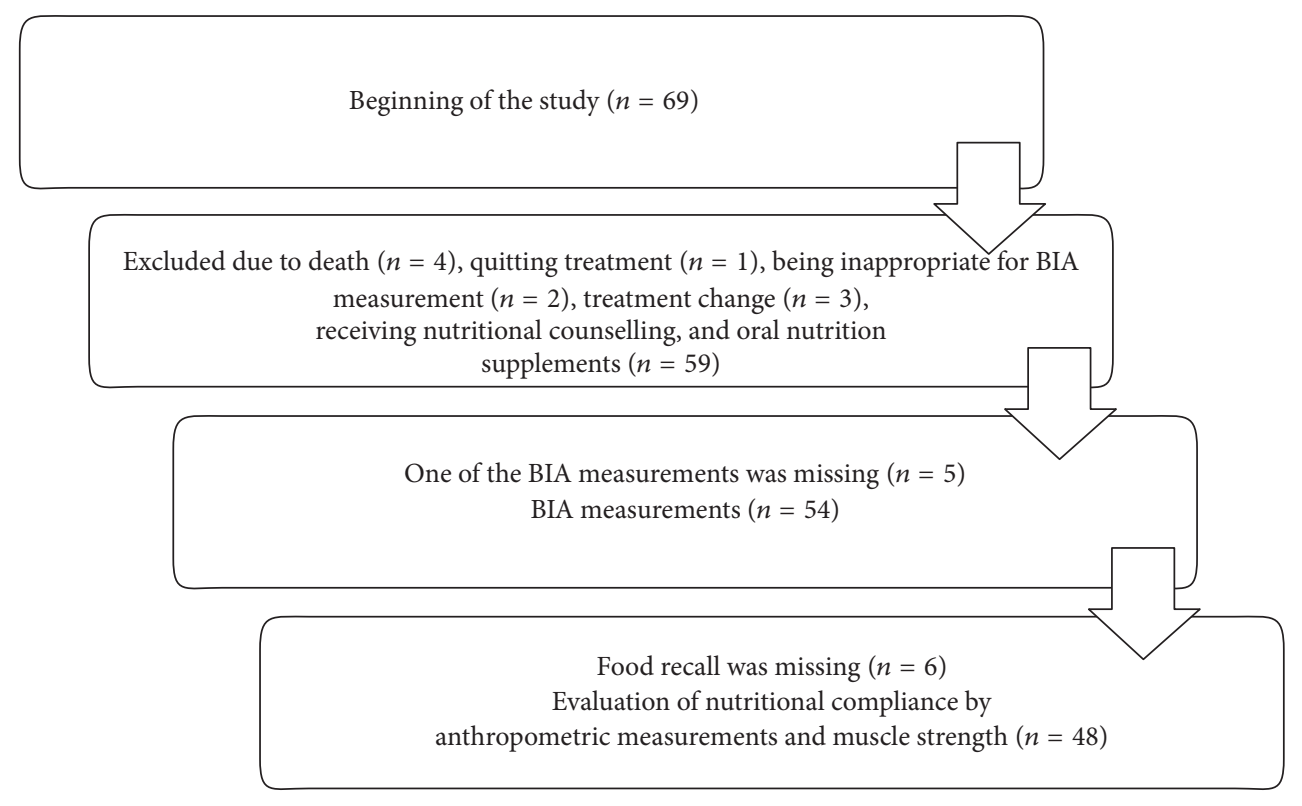

FIgURE 1: Flowchart of the study.

immunoresistance. The prevention as well as early diagnosis of malnutrition is of the utmost importance in such patients [6-8]. Tailoring of nutritional support for cancer patients at the beginning of treatment can improve the patient's quality of life by maintaining body weight and helping a range of issues in order to tolerate the treatment $[9,10]$.

The aim of this prospective study was to evaluate the effect of compliance with individual dietary counselling provided by the dietitian on body composition and anthropometry in HNC patients under RT.

\section{Material and Methods}

2.1. Study Population. A total of 69 ambulatory or hospitalized patients with HNC who were referred to the Department of Radiation Oncology for adjuvant or definitive RT with or without $\mathrm{CT}$ and received nutritional counselling and oral nutritional supplements (ONS) during RT or CRT were enrolled in this prospective single-center study at Ege University Hospital, Izmir, Turkey. As shown in study flow chart (Figure 1), final study population was composed of 59 patients with exclusion of 10 patients from the study due to death $(n=$ $4)$, treatment withdrawal $(n=1)$, treatment alteration $(n=$ 3 ), and occurrence of a physical condition that might affect study parameters $(n=2)$.

Written informed consent was obtained from each subject following a detailed explanation of the objectives and protocol of the study which was conducted in accordance with the ethical principles stated in the "Declaration of Helsinki" and approved by the Ege University Ethics Committee.

2.2. Study Parameters. Data on baseline characteristics (diagnosis, disease stage, type of chemotherapy, and surgery), percent weight loss, and ONS consumption characteristics (type of ONS, regular/irregular consumption, and reasons for irregular consumption) were recorded in each patient. Anthropometrics [body weight (kg), body mass index (BMI; $\left.\mathrm{kg} / \mathrm{m}^{2}\right)$ ] and body composition parameters [\% fat, fat mass $(\mathrm{kg})$, fat free mass $(\mathrm{kg})$, and muscle mass $(\mathrm{kg})]$, muscle function (hand grip strength), and severity of mucositis were evaluated according to patient compliance with nutritional intervention.

In 5 out of 59 patients one of the BIA measurements was missing; thus anthropometric measurements were evaluated in 54 patients. Food recall was missing in 6 patients and the association of nutritional compliance with anthropometric measurements and muscle strength was assessed in 48 patients (Figure 1).

Anthropometric and bioelectrical impedance analysis (BIA) measurements were performed at baseline (in the first day of treatment), in the middle of, and at the end of the treatment. Body weight $(\mathrm{kg}), \mathrm{BMI}\left(\mathrm{kg} / \mathrm{m}^{2}\right)$, fat percentage, fat mass (FM), fat-free mass (FFM), and muscle mass (MM) were measured using TANITA (Tanita Body Composition Analyzer SC 330 Japan). Grip strength was measured as identified of muscle strength, by means of a hand dynamometer (GripD T.K.K.5401 Japan) in a sitting position, on the nondominant hand, and with the elbow fixed at 90 degrees three consecutive times and the mean was taken for analysis. Mucositis was evaluated according to Radiation Therapy Oncology Group (RTOG) toxicity criteria [11].

2.3. RT with or without CRT. Patients were treated with intensity-modulated RT or three-dimensional conformal RT. Patients received radiation doses that ranged from 60 to $70 \mathrm{~Gy}$. The chemotherapeutic regimen included three cycles of neoadjuvant cisplatin $\left(75 \mathrm{mg} / \mathrm{m}^{2}\right)$ and docetaxel $\left(75 \mathrm{mg} / \mathrm{m}^{2}\right)$, followed by three weekly cisplatin $\left(75 \mathrm{mg} / \mathrm{m}^{2}\right)$ concurrently with RT or weekly cisplatin $\left(40 \mathrm{mg} / \mathrm{m}^{2}\right)$ with RT 
or cetuximab (one cycle of neoadjuvant $400 \mathrm{mg} / \mathrm{m}^{2}$ followed by $250 \mathrm{mg} / \mathrm{m}^{2}$ weekly with $\mathrm{RT}$ ).

\subsection{Nutritional Counselling and Oral Nutritional Supple-} ments. All patients received nutritional counselling during RT or CRT. Dietary counselling was provided by the same dietitian before, in the middle of, and at the end of RT with approximately two-week intervals. Regular and nutritional counselling was provided to each patient in accordance with their individual requirements based on the extent of their malnutrition, the prognosis and stage of their illness, and the side effects of treatment. Individually intended sample meal plans, recipe advices, and suggestions in order to minimise the side effects of the tumour and therapy such as mucositis, nausea, or vomiting were provided. Oral hypercaloric nutritional supplements and protein supplements were also provided. When symptoms such as dysphagia, swallowing difficulties, appetite loss, nausea, taste problems, or xerostomia were developed under RT, the individualised dietary modification was implemented to meet patients' needs.

Mean energy and protein intake were calculated from three-day food recall. Each patient was instructed by the dietician on how to fill in the diary. Dietary records were analyzed for energy and protein content using countryspecific food composition tables for Turkey [12].

Three-day food recall was taken consequently in the middle of the treatment, when the second anthropometric measurement was conducted. Energy and protein intake per unit weight were calculated for mean energy and protein intake divided by weight obtained from the second measurement. If the patient consumed $\geq 75 \%$ of the recommended energy and protein by taking ONS and regular food, he/she was considered as a "compliant patient" while those who consumed $<75 \%$ of the recommended energy and protein via ONS or regular food were considered to be "noncompliant patients." Patients having problems like pain, mucositis, swallowing difficulties, diarrhea, bad taste, and loss of appetite were also considered as noncompliant.

2.5. Statistical Analysis. Continuous variables were presented as means \pm standard deviation and categorical variables were summarized as percentages. Effect of regular consumption of ONS on total energy and protein intake was determined by chi-square and Mann-Whitney $U$ test. Change in anthropometric measurements and body composition (weight, fat free mass, fat mass, fat $\%$, muscle, and BMI) and muscle strength within time in compliant and noncompliant patients were evaluated via Friedman Repeated measurements, whereas the association between mucositis and consumption was determined by chi-square test. Data were analyzed using SPSS version 15.0 software. Significance was defined as $p<0.05$.

\section{Results}

In total 59 patients were evaluated. Among them, $79.7 \%$ were male and the mean age was $61.0 \pm 13.8$. Patient characteristics are shown in Table 1.

As shown in Table 1, half (49.2\%) of the patients had larynx-hypopharynx cancer at various stages. Most of the
TABLE 1: Baseline characteristics of patients.

\begin{tabular}{|c|c|c|}
\hline & $n$ & $\%$ \\
\hline \multicolumn{3}{|l|}{ Diagnosis } \\
\hline Larynx-hypopharynx & 29 & 49.2 \\
\hline Oral cavity & 8 & 13.6 \\
\hline Nasopharynx & 5 & 8.4 \\
\hline Paranasal sinus tumors & 5 & 8.4 \\
\hline Oropharynx & 4 & 6.8 \\
\hline Other & 8 & 13.6 \\
\hline \multicolumn{3}{|l|}{ Stage } \\
\hline 1 & 7 & 11.9 \\
\hline 2 & 15 & 25.4 \\
\hline 3 & 17 & 28.8 \\
\hline 4 & 20 & 33.9 \\
\hline \multicolumn{3}{|l|}{ Type of chemotherapy } \\
\hline None & 21 & 35.6 \\
\hline Weekly cisplatin & 26 & 44.1 \\
\hline $\begin{array}{l}\text { Neoadjuvant cisplatin-docetaxel followed } \\
\text { by } 3 \text { weekly cisplatin with concurrent RT }\end{array}$ & 10 & 16.9 \\
\hline Weekly cetuximab & 2 & 3.4 \\
\hline \multicolumn{3}{|l|}{ Operation type } \\
\hline None & 31 & 52.5 \\
\hline Mass excision & 9 & 15.3 \\
\hline Mass excision \& cervical dissection & 19 & 32.2 \\
\hline
\end{tabular}

patients (94.9\%) had squamous cell cancer type tumours. Mean RT duration was $43.5 \pm 5.6$ days. Only three of the patients had diabetes, and one had hypertension.

The percent weight loss of patients at onset of RT (according to their usual weight), the recommended ONS, consumption status, and main reasons for nonconsumption of ONS of the patients are presented in Table 2.

Hypercaloric ONS was recommended for majority of patients (94.6\%), while only $55.4 \%$ of patients were identified to consume ONS on a regular basis. Gastrointestinal disorders were the main reason for irregular ONS consumption (Table 2).

Three-day food recall could not be received from six patients. Thus daily energy and protein intake were evaluated in 53 patients. Mean daily energy and protein intake were $1518.8 \pm 522.5 \mathrm{kCal}$ and $66.1 \pm 30.3$ grams, respectively. When patients' weight was considered, mean energy and protein intake per unit weight were $21.8 \pm 9.3 \mathrm{kCal}$ and $0.95 \pm 0.5$ grams, respectively. Thirty-two patients $(60.4 \%)$ had sufficient energy intake and twenty-one patients (39.6\%) had sufficient protein intake. Thus, 20 patients (38\%) who consumed sufficient ( $\geq 75 \%$ of their requirements) energy and protein were considered to be "compliant" (data on BIA measurements were not available in 2 patients). Consumption did not meet the criteria of $\geq 75 \%$ of the recommended energy and protein intake in $62 \%(n=33)$ of patients, who were therefore considered to be "noncompliant" (data on BIA measurements were not available in 3 patients). 
TABle 2: Percent loss of weight and ONS consumption in overall study population.

\begin{tabular}{lcc}
\hline & $n$ & $\%$ \\
\hline Weight loss compared to normal weight (\%) & 31 & 52.6 \\
None & 17 & 28.8 \\
$<10 \%$ & 11 & 18.6 \\
$\geq 10 \%$ & & \\
Type of enteral product recommended ( $n=56)$ & 53 & 94.6 \\
Hypercaloric & 3 & 5.4 \\
Diabetic & & \\
Consumption of the recommended ONS $(n=56)$ & 31 & 55.4 \\
Regularly & 25 & 44.6 \\
Not regularly & & \\
Reasons for nonconsumption ( $n=28)$ & 14 & 50.0 \\
Loss of appetite, nausea \& diarrhoea & & \\
Personal reasons (bad taste, not believing the & 5 & 17.8 \\
importance of it) & 5 & 17.8 \\
Pain during swallowing & 4 & 14.4 \\
\hline Not stated
\end{tabular}

Mean total and per unit weight energy $[1977.1 \pm 385.3 \mathrm{kcal}$ $(29.3 \pm 7.1 \mathrm{kcal} / \mathrm{kg})$ versus $1240.9 \pm 380.2 \mathrm{kcal}(17.2 \pm$ $72 \mathrm{kcal} / \mathrm{kg}), p<0.001]$ and protein $[97.8 \pm 16.6 \mathrm{gr}(1.5 \mathrm{~g}$ $\pm 0.4 \mathrm{gr} / \mathrm{kg})$ versus $46.8 \pm 17.8 \mathrm{gr}(0.6 \pm 0.3 \mathrm{gr} / \mathrm{kg}), p<$ 0.001] intake were significantly higher in compliant than in noncompliant patients. Similarly, regular ONS consumers had significantly higher intake of energy per unit weight $(p<$ $0.001)$ and protein per unit weight $(p<0.001)$. Three patients had nasogastric tube whereas 4 had percutaneous endoscopic gastrostomy (PEG).

Nine patients were hospitalized, 29 patients were staying at home or with relatives, and 11 were staying at a hotel during the treatment period. Compared to those staying in a hotel, those staying at home or with relatives had significantly higher energy intake ( $p=0.009$ ), while no significant difference was noted with respect to protein intake.

No significant difference was noted between compliant and noncompliant patients at baseline in terms of BMI, weight, fat percentage, fat mass, fat free mass, muscle mass, and hand grip strength. Change in body composition over the time is presented in Table 3.

No significant change was noted in BMI, weight, fat percentage, fat mass, fat free mass, and muscle mass values over the time in compliant patients, whereas in noncompliant patients all these indices decreased significantly from baseline to the end of the treatment $(p<0.001)$.

Hand grip strength at baseline was similar in compliant and noncompliant patients. Also, no significant change was noted in hand grip strength from baseline to the end of treatment in both groups.

During treatment, an undesired complication, oral mucositis was recorded in $91.5 \%$ of 48 patients with available data. The effect of compliance status of the patient on the degree of mucositis (light: first degree and second degree; heavy: third degree and fourth degree) was shown in Table 4.
More than one-third (40.7\%) of the patients developed second-degree mucositis and one-third of the $(30.5 \%)$ patients developed third-degree mucositis. Heavy mucositis was significantly less common in compliant than in noncompliant patients $(p<0.009)$.

\section{Discussion}

Malnutrition is frequently seen in HNC patients and it plays a multifactorial role in the progression of the disease. A high rate of tobacco and alcohol use, the lack of a regular lifestyle [13], difficulties in swallowing as a result of the anatomical position of the tumour and the morbidity of the HNC surgery [14], RT dose, sense problems, nausea/vomiting, pain, dry mouth, and having trouble with social eating are significantly associated with malnutrition [2]. In particular, the dysphagia and mucositis due to toxicity of high doses of curative RT were shown to cause a vicious cycle of malnutrition [15]. In a past study malnutrition rates were reported to be $24 \%$ before RT, while it was $88 \%$ after RT [4]. Weight loss during RT or CRT is a substantial problem in HNC patients and it is accompanied by loss of fat free mass, muscle and organ mass, deterioration in quality of life, more severe treatmentinduced toxicity, and a shorter survival $[16,17]$.

There are beneficial effects of individualized dietary counselling on nutritional status compared to lack of counselling or standard nutritional advice [10]. According to the European Society for Clinical Nutrition and Metabolism [18], the purpose of nutrition counselling and nutritional supplement is to prevent the deterioration of nutrition during treatment and to treat when necessary to reduce treatmentrelated toxicity and to increase the effectiveness of cancer treatment as well as the quality of life.

In this study, body weight, body composition (muscle mass, fat percentage, fat mass, and fat free mass), and muscle function (hand grip strength) of compliant and noncompliant patients were compared. It was found that $37.5 \%$ of patients in our study complied with the recommended nutrition plan, but $62.5 \%$ did not, for various reasons. The two groups had similar sociodemographic characteristics. The change in BMI, weight, fat mass, fat free mass, and muscle mass during RT was insignificant in compliant patients whereas, in noncompliant patients, there was a dramatic and significant decrease in these measurements during treatment $(p<$ 0.001).

Many clinics place a PEG prophylactically before starting RT in order to prevent weight loss and treatment toxicity $[19,20]$, while it may regress swallowing function in the long term and may lead to a delay in nutrition via oral route in some patients [21]. Although PEG tube has been suggested to be a more suitable route for enteral nutrition in $\mathrm{HNC}$ patients than the NG tube [22], the likelihood of development of complications has also been emphasized [23]. In our cohort, nasogastric feeding tube was applied to three patients and PEG was applied to four patients with full indications.

Nutritional counselling and supplemented oral feeding at the start of treatment have gained great importance. Research has shown that more than $80 \%$ of HNC patients develop dysphagia under CRT, and $10 \%$ or more lose weight [24]. It 
TABLE 3: Anthropometric and body composition parameters with respect to compliance.

\begin{tabular}{|c|c|c|c|c|c|c|c|c|}
\hline & \multicolumn{4}{|c|}{ Compliant patients $(n=18)$} & \multicolumn{4}{|c|}{ Noncompliant patients $(n=30)$} \\
\hline & Baseline & Middle of treatment & End of treatment & $p$ & Baseline & Middle of treatment & End of treatment & $p$ \\
\hline BMI $\left(\mathrm{kg} / \mathrm{m}^{2}\right)$ & $25.6 \pm 4.2$ & $25.4 \pm 4.3$ & $25.3 \pm 4.3$ & 0.536 & $26.9 \pm 4.5$ & $26.0 \pm 4.4$ & $24.6 \pm 4.3^{*}$ & $<0.001$ \\
\hline Weight & $68.7 \pm 14.9$ & $69.2 \pm 14.9$ & $68.6 \pm 14.4$ & 0.666 & $76.1 \pm 14.3$ & $71.3 \pm 13.6$ & $67.5 \pm 13.0^{*}$ & $<0.001$ \\
\hline$\%$ fat & $24.1 \pm 10.1$ & $23.8 \pm 9.6$ & $23.4 \pm 9.2$ & 0.744 & $25.3 \pm 8.2$ & $26.0 \pm 8.8$ & $23.6 \pm 9.2^{*}$ & $<0.001$ \\
\hline $\mathrm{FM}(\mathrm{kg})$ & $17.6 \pm 9.4$ & $17.4 \pm 8.9$ & $16.8 \pm 8.2$ & 0.906 & $19.2 \pm 8.1$ & $18.8 \pm 8.1$ & $16.4 \pm 7.8^{*}$ & $<0.001$ \\
\hline FFM (kg) & $51.1 \pm 8.3$ & $51.7 \pm 8.6$ & $51.7 \pm 9.1$ & 0.568 & $54.9 \pm 9.9$ & $52.6 \pm 9.6$ & $51.2 \pm 9.5^{*}$ & $<0.001$ \\
\hline Muscle mass (kg) & $48.6 \pm 7.9$ & $49.1 \pm 8.8$ & $49.1 \pm 8.7$ & 0.568 & $52.1 \pm 9.5$ & $49.9 \pm 9.2$ & $48.6 \pm 9.1^{*}$ & $<0.001$ \\
\hline
\end{tabular}

48 patients with three BIA measurements and a food recall were evaluated; Friedman repeated measures; FM: fat mass; FFM: fat free mass (*) $p<0.001$ when compared to baseline values.

TABLE 4: Severity of mucositis with respect to compliance.

\begin{tabular}{lccccc}
\hline & \multicolumn{2}{c}{ Compliant patients } & \multicolumn{3}{c}{ Noncompliant patients } \\
& $n$ & $\%$ & $N$ & & \\
\hline Light mucositis $(n=30)$ & 16 & 53.3 & 14 & 46.7 \\
Heavy mucositis $(n=18)$ & 2 & 11.1 & 16 & 88.9 \\
\hline
\end{tabular}

Chi-square; $p=0.009$.

has been necessary to suspend treatment because of severe mucositis in $20 \%$ of patients [25].

In a previous study in 78 patients with $\mathrm{HNC}$ and gastrointestinal cancer by Isenring et al. [26], while minimal weight loss was reported with nutritional supplements, a significant reduction in body weight occurred with standard nutrition. Other studies have shown the benefits of nutritional supplements on fat free mass [10,27, 28]. In our study fat percentage, fat mass and fat free mass remained unaltered in compliant patients during treatment, whereas they decreased significantly among noncompliant patients during the treatment period.

We assessed nutrition consumption for three consecutive days (two during the week and one at the weekend) in the middle of treatment. Recording of three-day nutrition consumption is important in order to determine energy and protein deficit. We found that the daily energy and protein intake of compliant patients were greater than those of noncompliant patients. The nature of living conditions of patients during RT is important with regard to their food consumption. In our study, compared to those staying in a hotel, patients staying at home or staying with relatives had significantly more sufficient energy intake. This may indicate the higher likelihood of a precise care provided by family or relatives of patients. Both economical issues and desolation of patients receiving RT are important factors in terms of quality of food consumption.

In the present study, no significant muscle loss was observed in compliant patients during RT, but a significant loss was determined in noncompliant patients. Albeit not significant, tendency for similar findings was also noted for muscle function. This may be associated with small sample size and the short-term follow-up period in our study.

In a past study with 75 patients receiving RT for HNC by Ravasco et al. [3], it was shown that merely adding supplement products to a patient's diet was not as effective as dietary counselling. Paccagnella et al. [29] reported that early nutritional intervention in patients with HNC under CRT was associated with an improved treatment tolerance. We observed that mucositis was less severe among patients who complied with nutritional counselling and recommendations than noncompliant patients. The importance of oral nutrition supplement on the toxicity of RT was investigated in a prospective study by Valentini et al. [30]. Radiotherapyrelated grade 3 toxicity was found to be greater in those with weight loss, reduced mid-arm circumference, or low serum albumin levels [30]. In our study, no significant weight loss was observed in patients who regularly used the recommended oral nutrition products.

The major strength of this study is, by using BIA prospectively in a special patient population, to present how the nutritional intake may impact body composition such as fat percentage, fat mass, fat free mass, and muscle mass in compliant and noncompliant head and neck cancer patients undergoing RT. Regarding the limitations in our study, we did not monitor nutritional status after completion of RT; thus we did not know whether nutritional status affected the clinician's decision to continue RT. Another limitation is that we considered mucositis being the most important factor on patient's intake and we evaluated only mucositis among the potential factors that may influence good compliance to the dietary treatment.

In conclusion, body composition parameters were better in head and neck cancer patients considered as compliant according to dietary intake than noncompliant ones during radiotherapy period. Further studies addressing cancer symptom management are needed to improve nutritional status and cancer patients should be monitored for malnutrition not only during radiotherapy but also after the completion of treatment. 


\section{Competing Interests}

The authors declare that they have no conflict of interests.

\section{References}

[1] M. R. Chasen and R. Bhargava, "A descriptive review of the factors contributing to nutritional compromise in patients with head and neck cancer," Supportive Care in Cancer, vol. 17, no. 11, pp. 1345-1351, 2009.

[2] J. A. E. Langius, P. Doornaert, M. D. Spreeuwenberg, J. A. Langendijk, C. R. Leemans, and M. A. E. V. B.-D. V. D. Schueren, "Radiotherapy on the neck nodes predicts severe weight loss in patients with early stage laryngeal cancer," Radiotherapy and Oncology, vol. 97, no. 1, pp. 80-85, 2010.

[3] P. Ravasco, I. Monteiro-Grillo, P. M. Vidal, and M. E. Camilo, "Impact of nutrition on outcome: a prospective randomized controlled trial in patients with head and neck cancer undergoing radiotherapy," Head and Neck, vol. 27, no. 8, pp. 659-668, 2005.

[4] D. Unsal, B. Mentes, M. Akmansu, A. Uner, M. Oguz, and Y. Pak, "Evaluation of nutritional status in cancer patients receiving radiotherapy: a prospective study," American Journal of Clinical Oncology, vol. 29, no. 2, pp. 183-188, 2006.

[5] J. H. Lee, M. Machtay, L. D. Unger et al., "Prophylactic gastrostomy tubes in patients undergoing intensive irradiation for cancer of the head and neck," Archives of Otolaryngology - Head and Neck Surgery, vol. 124, no. 8, pp. 871-875, 1998.

[6] J. J. Reilly Jr., S. F. Hull, N. Albert, A. Waller, and S. Bringardener, "Economic impact of malnutrition: a model system for hospitalized patients," Journal of Parenteral and Enteral Nutrition, vol. 12, no. 4, pp. 371-376, 1988.

[7] W. D. Dewys, C. Begg, P. T. Lavin et al., "Prognostic effect of weight loss prior tochemotherapy in cancer patients," The American Journal of Medicine, vol. 69, no. 4, pp. 491-497, 1980.

[8] M. G. A. Van den Berg, E. L. Rasmussen-Conrad, K. H. Wei, H. Lintz-Luidens, J. H. A. M. Kaanders, and M. A. W. Merkx, "Comparison of the effect of individual dietary counselling and of standard nutritional care on weight loss in patients with head and neck cancer undergoing radiotherapy," British Journal of Nutrition, vol. 104, no. 6, pp. 872-877, 2010.

[9] P. Ravasco, I. M. Grillo, and M. Camilo, "Cancer wasting and quality of life react to early individualized nutritional counselling!," Clinical Nutrition, vol. 26, no. 1, pp. 7-15, 2007.

[10] J. A. E. Langius, M. C. Zandbergen, S. E. J. Eerenstein et al., "Effect of nutritional interventions on nutritional status, quality of life and mortality in patients with head and neck cancer receiving (chemo)radiotherapy: a systematic review," Clinical Nutrition, vol. 32, no. 5, pp. 671-678, 2013.

[11] A. Trotti, R. Byhardt, J. Stetz et al., "Common toxicity criteria: version 2.0. An improved reference for grading the acute effects of cancer treatment: impact on radiotherapy," International Journal of Radiation Oncology, Biology, Physics, vol. 47, no. 1, pp. 13-47, 2000.

[12] A. Baysal, S. Keçecioglu, P. Arslan et al., Besinlerin Bileşimleri, Turkish Dietitian Assosiation Press, Ankara, Turkey, 1991.

[13] M. L. Gillison, "Current topics in the epidemiology of oral cavity and oropharyngeal cancers," Head and Neck, vol. 29, no. 8, pp. 779-792, 2007.

[14] N. Choong and E. Vokes, "Expanding role of the medical oncologist in the management of head and neck cancer," $C A$ Cancer Journal for Clinicians, vol. 58, no. 1, pp. 32-53, 2008.
[15] S. Garg, J. Yoo, and E. Winquist, "Nutritional support for head and neck cancer patients receiving radiotherapy: a systematic review," Supportive Care in Cancer, vol. 18, no. 6, pp. 667-677, 2010.

[16] J. Bernier, C. Domenge, M. Ozsahin et al., "Postoperative irradiation with or without concomitant chemotherapy for locally advanced head and neck cancer," New England Journal of Medicine, vol. 350, no. 19, pp. 1945-1952, 2004.

[17] J. S. Cooper, T. F. Pajak, A. A. Forastiere et al., "Postoperative concurrent radiotherapy and chemotherapy for high-risk squamous-cell carcinoma of the head and neck," The New England Journal of Medicine, vol. 350, no. 19, pp. 1937-1944, 2004.

[18] J. Arends, G. Bodoky, F. Bozzetti et al., "ESPEN guidelines on enteral nutrition: non-surgical oncology," Clinical Nutrition, vol. 25, no. 2, pp. 245-259, 2006.

[19] M. Schattner, "Enteral nutritional support of the patient with cancer: route and role," Journal of Clinical Gastroenterology, vol. 36, no. 4, pp. 297-302, 2003.

[20] J. H. Lee, M. Machtay, L. D. Unger et al., "Prophylactic gastrostomy tubes in patients undergoing intensive irradiation for cancer of the head and neck," Archives of OtolaryngologyHead and Neck Surgery, vol. 124, no. 8, pp. 871-875, 1998.

[21] M. O. F. Al-Othman, R. J. Amdur, C. G. Morris, R. W. Hinerman, and W. M. Mendenhall, "Does feeding tube placement predict for long-term swallowing disability after radiotherapy for head and neck cancer?" Head and Neck, vol. 25, no. 9, pp. 741-747, 2003.

[22] T. M. Mekhail, D. J. Adelstein, L. A. Rybicki, M. A. Larto, J. P. Saxton, and P. Lavertu, "Enteral nutrition during the treatment of head and neck carcinoma. Is a percutaneous endoscopic gastrostomy tube preferable to a nasogastric tube?" Cancer, vol. 91, no. 9, pp. 1785-1790, 2001.

[23] J. L. Locher, J. A. Bonner, W. R. Carroll et al., "Prophylactic percutaneous endoscopic gastrostomy tube placement in treatment of head and neck cancer: a comprehensive review and call for evidence-based medicine," Journal of Parenteral and Enteral Nutrition, vol. 35, no. 3, pp. 365-374, 2011.

[24] L. A. Newman, F. Vieira, V. Schwiezer et al., "Eating and weight changes following chemoradiation therapy for advanced head and neck cancer," Archives of Otolaryngology-Head and Neck Surgery, vol. 124, no. 5, pp. 589-592, 1998.

[25] A. Trotti, L. A. Bellm, J. B. Epstein et al., "Mucositis incidence, severity and associated outcomes in patients with head and neck cancer receiving radiotherapy with or without chemotherapy: a systematic literature review," Radiotherapy and Oncology, vol. 66, no. 3, pp. 253-262, 2003.

[26] E. A. Isenring, S. Capra, and J. D. Bauer, "Nutrition intervention is beneficial in oncology outpatients receiving radiotherapy to the gastrointestinal or head and neck area," British Journal of Cancer, vol. 91, no. 3, pp. 447-452, 2004.

[27] H. G. Weed, M. L. Ferguson, R. L. Gaff, D. S. Hustead, J. L. Nelson, and A. C. Voss, "Lean body mass gain in patients with head and neck squamous cell cancer treated perioperatively with a protein- and energy-dense nutritional supplement containing eicosapentaenoic acid," Head and Neck, vol. 33, no. 7, pp. 10271033, 2011.

[28] P. E. May, A. Barber, J. T. D’Olimpio, A. Hourihane, and N. N. Abumrad, "Reversal of cancer-related wasting using oral supplementation with a combination of $\beta$-hydroxy- $\beta$ methylbutyrate, arginine, and glutamine," The American Journal of Surgery, vol. 183, no. 4, pp. 471-479, 2002. 
[29] A. Paccagnella, M. Morello, M. C. Da Mosto et al., "Early nutritional intervention improves treatment tolerance and outcomes in head and neck cancer patients undergoing concurrent chemoradiotherapy," Supportive Care in Cancer, vol. 18, no. 7, pp. 837-845, 2010.

[30] V. Valentini, F. Marazzi, M. Bossola et al., "Nutritional counselling and oral nutritional supplements in head and neck cancer patients undergoing chemoradiotherapy," Journal of Human Nutrition and Dietetics, vol. 25, no. 3, pp. 201-208, 2012. 


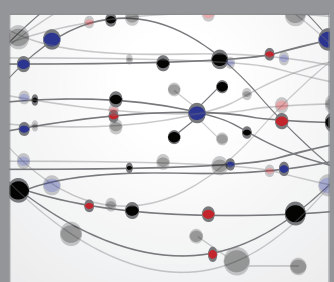

The Scientific World Journal
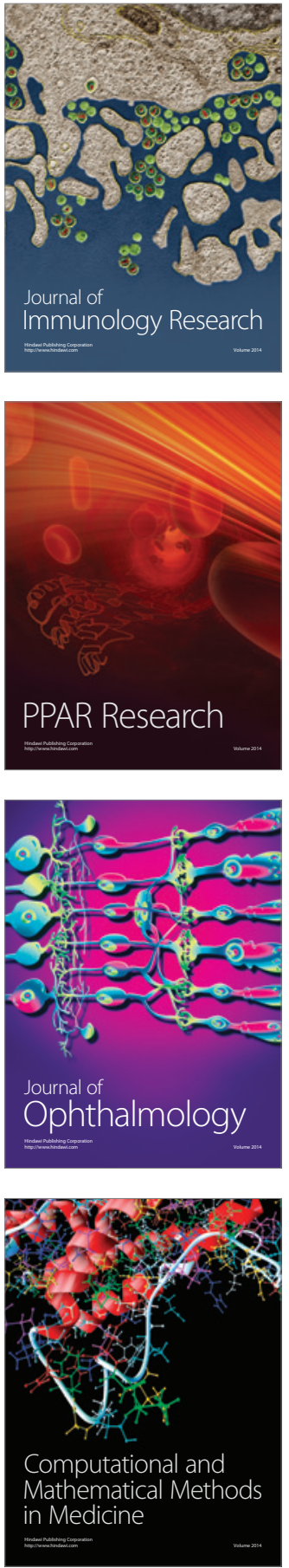

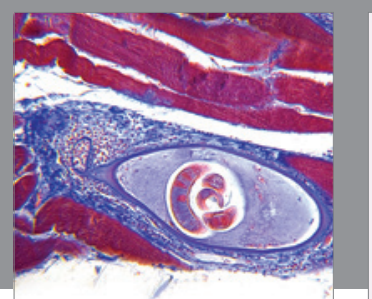

Gastroenterology Research and Practice
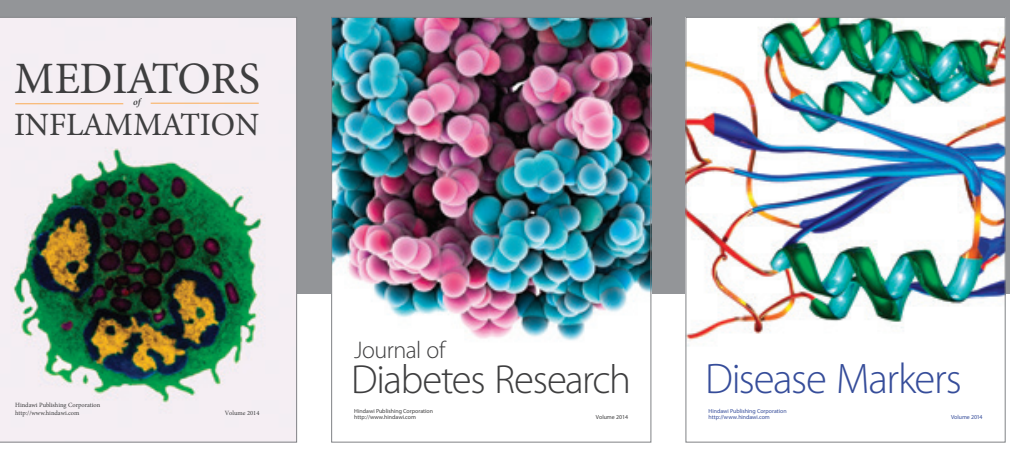

Disease Markers

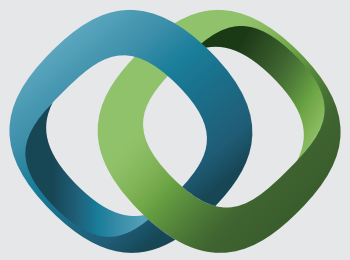

\section{Hindawi}

Submit your manuscripts at

https://www.hindawi.com
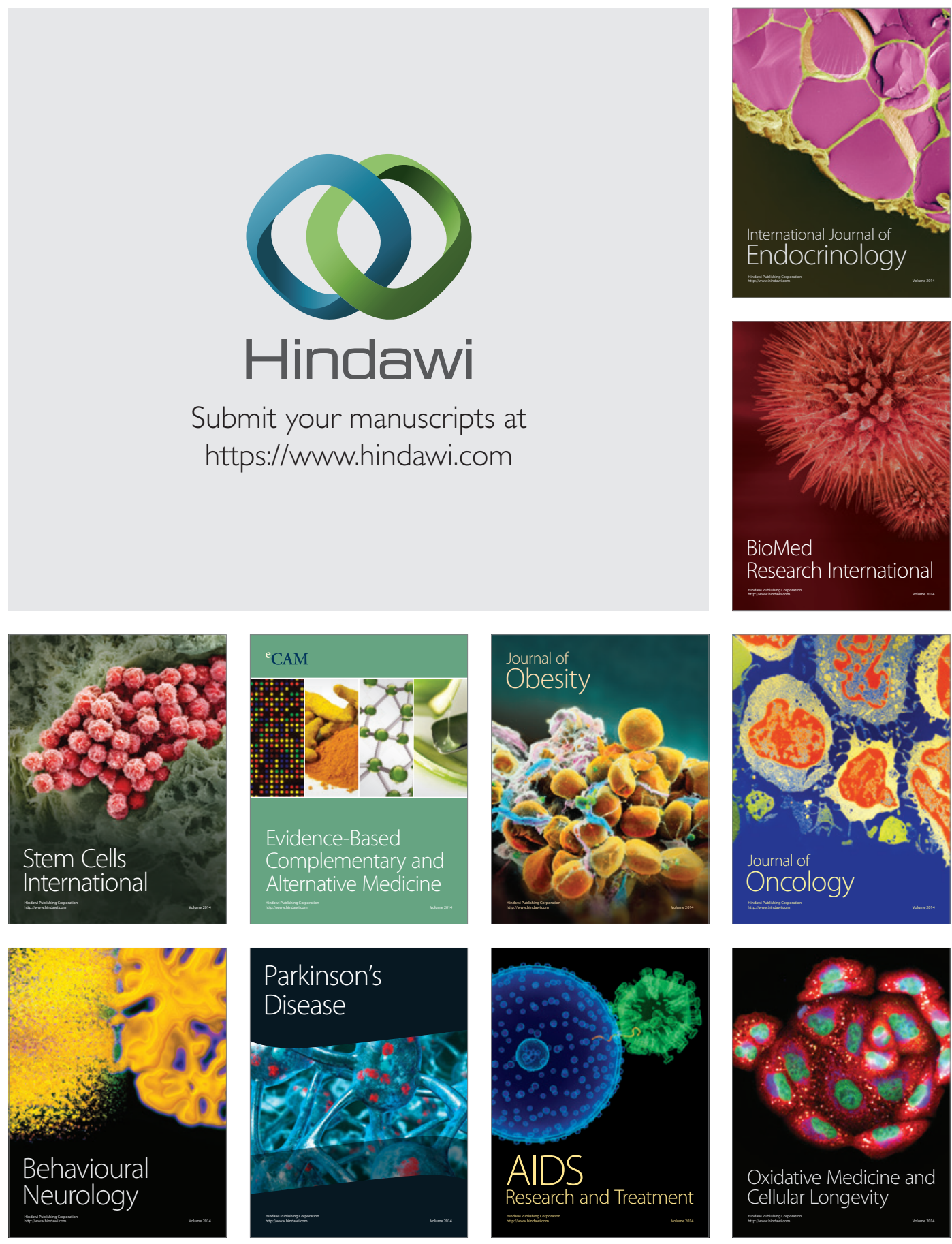